\title{
The Historical and Cultural Dimensions in Grammar Formation: The Case of Modern Greek
}

Brian D. Joseph

\begin{abstract}
In formulating grammatical descriptions, there is a natural and understandable tendency to focus solely on synchronic structural elements, based on the quite reasonable assumptions that structure is crucial to grammar and that coherent descriptions are possible only for one stage of a language at a time. Thus diachrony becomes irrelevant and extraneous to the goal of typology, under that view. Similarly, for those interested in structure, the existence of socially determined variation in usage can pose particular problems, to the point where ignoring variation may be a methodological necessity, at least for certain types of theorizing. It is argued here, however, that one cannot ignore socio-cultural and historical aspects involved in the process of grammar formation, as engaged in both by speakers and by analysts interested in compiling a grammar. An investigation is undertaken here of the case of Modern Greek, as a speech community with a long tradition of grammatical description, strong prescriptive attitudes, and a pervasive awareness among speakers as to the historicity of their language, factors which together have impinged on and influenced both the modern linguist-grammarian and the native users of the language. In particular, just as the speaker is confronted with choices between innovative and conservative forms - the latter accessible, for instance, through archaizing registers and texts - the analyst is confronted with the need to take into account the lengthy descriptive heritage and the classicizing prescriptive notions, and faces the dilemma of deciding whether to strip them away or to incorporate them into the grammatical account. In a sense, then, history and attitudes can push typological limits, a key issue in developing accounts of human language in general, and of human languages in particular.
\end{abstract}

It is well-known that typologists, like the languages they investigate, come in different types. All are interested in the nature of human language, yet some get at that elusive goal by focusing on familiar languages, in an attempt to draw on the typically wider range of resources - not to mention 
speakers - available for well-known languages. In addition, though, there are typologists who look to unfamiliar languages, often - and somewhat Eurocentrically to be sure - called "exotic" and in any case generally poorly known or previously undescribed. The honorand to whom this volume is dedicated is clearly a typologist of the second stripe, and indeed, R. M. W. ("Bob") Dixon has devoted the better part of his impressive scholarly career to extending our knowledge of human language by examining in exquisite detail an impressive number of otherwise under- (or un-)described languages, some of which qualify as exotic by any criterion.

There is a natural and understandable interest on the part of many typologists to focus on the less-known languages — and large numbers of them - based on the quite reasonable assumption that these languages offer the greatest potential for insights into the nature of human language that go beyond what familiar languages have provided to date. There is also the practical concern that many of these languages are endangered and thus must be examined now if they are ever to provide any insights.

At the same time, though, investigating in depth even a single language, and a well-known one at that, can yield unexpected insights: for instance, as Zwicky \& Pullum 1983 have noted, Maling 1983 made the interesting discovery of a new word-class - the transitive adjective based on her analysis of the English word near in phrases such as near the 
barn as being an adjective (note the comparative and superlative forms nearer and nearest) and further being one that therefore (and somewhat surprisingly) takes a direct object, rather than a preposition (as it has generally been treated traditionally ${ }^{\mathrm{i}}$ in this use). ${ }^{\mathrm{ii}}$ Moreover, in any case, Universal Grammar must be broad enough to accommodate and allow for data from any language, whether well-known or not, so that in principle we can learn about the limits and the content of Universal Grammar from surveying familiar languages and even from examining individual languages. ${ }^{i i i}$

Thus, it would seem that there is some merit to both approaches to investigating linguistic typology — that looking to exotica and that looking to the familiar — and thereby developing a sense of what "Universal Grammar" entails. At the same time, each way of engaging in typological investigation has as well its own associated set of problems. For instance, poorly described and little-known languages typically are off the beaten path and often require extraordinary means on the part of a researcher simply to be able to encounter the language in use. Familiar languages tend to be more readily accessible — one of the reasons they are familiar, oftentimes - yet they are not unproblematic and they do present their own set of challenges. 
In this paper, by way of honoring Bob Dixon and his intense interest in grammar writing by linguist-observers, I explore the consequences, with particular attention to the potential pitfalls, of engaging in the exercise of grammar writing and typological investigation with a well-known language. The target language used here as the exemplar is Greek, which, next to English and Chinese, may just be the most thoroughly examined language around.

The problems with looking at well-known languages present themselves quite readily. In particular, with such languages, one often has to reckon with various assumptions and preconceptions being brought to the table when one goes to talk about and analyze them. That is, even though it might be desirable when looking to a given language for typological insight to approach that language with one's notebook, so to speak, a tabula rasa, such is simply not possible with well-known languages in this day and age - too much is already known and too much information is available about them. Preconceptions are thus inevitable. Such preconceptions, unfortunate as they are, arise most dramatically when there are traditions of grammatical analysis for the language that are too solidly ingrained in most analysts' heads and are too influential to allow for an unbiased appraisal of the facts can get in the way. 
Another sort of problem with familiar languages is that the analyst may know, or at least have an idea, what the language was like at an earlier stage in its development, so that the temptation is always there to base a synchronic analysis on the way the language was in an earlier stage. ${ }^{\text {iv }}$ The problem with such historical knowledge is that in formulating grammatical descriptions, there is a natural and understandable tendency to focus solely on synchronic structural elements, based on the quite reasonable assumptions that structure is crucial to grammar and that coherent descriptions are possible only for one stage of a language at a time. Thus, under such a view, diachrony should be irrelevant and extraneous to the goal of typology; nonetheless, the information is there to tempt the analyst and perhaps lead the analysis off the purely synchronic path.

These two problems are inter-related, in that knowledge of the history of the language can shape the assumptions that are made about the nature of particular items and constructions. Moreover, influential traditional views may well have been formed at a time, years or even centuries earlier, when the elements that are the focus of an investigation had a different status from their contemporary status.

For instance, it is customary to talk about the person markers of (especially colloquial) French, as in je vois / tu vois 'I/you see' as separate words and "free" pronouns, even though they are anything but free but 
rather function in ways quite similar to simple affixal elements, a type of agreement markers. ${ }^{v}$ Indeed, Sauvageot 1962: 29-30 provoked some degree of controversy with his suggestion that French subject + object + verb complexes such as je le vois 'I - him - see' could be analyzed as an agglutinative structure in a manner analogous to the usual treatment of the similar sequence in a language like Swahili (e.g. n-a-ki-ona 'I - present - it - see'). Similarly, the analogous subject markers in the Algonquian language Cree, as in ni-wapamaw / ki-wapamaw 'I/you see (him)', are unquestioningly referred to as personal prefixes (see Wolfart 1973), not as words. The view that the French elements such as je or $t u$ must be words and could not be affixes undoubtedly derives from the fact that these elements were free words at an earlier stage of the language, and the grammatical tradition of referring to them as such was fixed at a point where that was true - traditions, as we know, die hard (hence the controversy that Sauvegeot's assertions about these elements provoked). In the case of Cree (and Swahili, for that matter), there is no such tradition for Algonquian languages (or for Bantu) and no one is sure if the current prefixes ever were independent words; thus, the more realistic prefix labeling is generally used, and used uncontroversially.

As suggested above, these problems reflect a state of having too much knowledge about the target language. Excessive knowledge can also 
be problematic when it comes to variation, for the more an analyst knows about a language, the more likely it is that (s)he will become aware of variation in speakers' usage, whether socially determined or due to other causes. The existence of variation can pose particular problems for those interested in structure, since it can be unclear which of, say, two competing patterns to take as basic, which one to take as indicative of what the language is really like, and so on. For certain types of theorizing, at least, ignoring variation might be a methodological necessity. Relevant here is the notion from early on in generative grammar of the "ideal speakerhearer" and the concomitant view of variation as being merely a matter of performance, not one of linguistic competence. It might be better perhaps to see ignoring variation just as a starting point as one begins to get a handle on a language rather than as a guiding principle throughout an investigation. Still, ultimately, variation has to be confronted, and with well-known languages, it may be that the time for that confrontation has certainly come, certainly sooner than with less-studied languages about which details on variation might just be coming to light. ${ }^{\mathrm{vi}}$

In the case of Greek, one source of variation is its own history, in the form of an artificially archaizing variety of the language which took shape largely in the first half of the nineteenth century in the aftermath of the Greek revolution, in part to full a perceived need for a national 
language to accompany the emergence of the new Greek nation-state. This variety is the so-called katharevousa, or Puristic, Greek, which for decades, into the late $20^{\text {th }}$ century even, co-existed in a diglossic relationship (in the sense of Ferguson 1959, who used the Greek case as one of his primary examples) with so-called demotic Greek, the variety that developed naturally out of the Hellenistic Greek koine. Social pressures to use the high-style katharevousa variety in certain circumstances — public and largely official language such as speeches, lectures, governmental transactions, and the like - alongside the demotic led to intra- and interspeaker variation. ${ }^{\text {vii }}$ Thus, alongside demotic xtés for 'yesterday', the naturally evolved outcome of Hellenistic Greek $x \_e ́ s$, itself the natural outcome of Ancient Greek $k^{h} t^{h}$ és, one can also hear even today $x \_e ́ s$, with an initial cluster that more closely and directly reflects an earlier pronunciation than does xtés, with its further evolved initial cluster.

History, then, as far as Greek is concerned, is embedded in current usage and variability. Yet, ideally, even when considering a well-known language typologically, one would want to be able to take an a-historical viewpoint, so that there were no preconceptions coloring things and that the results are as "clean" as possible. The case of Greek shows why such a stance is needed. It is not unusual to find in discussions of Modern Greek grammar references to Ancient Greek. For instance, Kalitsunakis (1928: 
46), in his Grammatik der neugriechischen Volkssprache (emphasis added), includes statements like "Der altgriechische Genitiv is vielfach durch die Präposition_ $\pi_{-}[a p o ́]$ mit Akkusativ ersetzt worden”. viii Further, Holton, Mackridge, \& Philippaki-Warburton (1997: 159), in their brief discussion of the Modern Greek past-tense marker known as the augment (whence "augmentation" as the process by which it appears), include the following statement: "In Ancient Greek all past tenses of verbs had augmentation as a regular morphological feature. In Modern Greek augmentation, when it occurs, can be divided into ... three categories ...". In both of these statements, therefore, the authors felt that inclusion of some reference to the earlier state of affairs found in Ancient Greek, was useful for the readers of a grammar of the modern language.

Of course, it is clear why there are such statements - it is impossible to ignore the history of Greek and in many instances, as with the augment, a quick view of the history provides some insight, for instance into why the feature is sporadically realized in the modern language - it is on the way out and is largely just hanging on in a few places. Moreover, the simple fact of the existence of high-style (katharevousa) forms, taken together with the presence of katharevousa throughout much of the modern era, makes it essential for readers to be made aware of some of the historical background. In particular, since katharevousa, being a 
consciously archaizing variety, often contained features that more directly reflect Ancient Greek usage, the history of the language can be on display in contemporary usage and variation. Indeed, the katharevousa-style pronunciation $x \_e ́ s$ for 'yesterday' referred to above is a case in point.

Yet, it is also clear that such statements invite the inference that Ancient Greek provides the basic point of reference for things Hellenic. Yet, on the face of it, such statements can be viewed as somewhat odd. We do not describe indirect objects in French, for instance, by saying that the language lacks a dative case, even though Latin had a dative case to the same extent as Ancient Greek, and French and Modern Greek are comparable in terms of their relation to their respective parent language. Nor do we say such a thing about languages that may never have had a dative case; for example, the syntax of indirect objects in the Cree is described in the standard treatment of Cree grammar (Wolfart 1973) solely in terms of what the language actually does, not what it might do (or used to do).

Such historical statements in a synchronic description, especially when referring to the absence of a feature (as, for instance, if a grammar remarked on the absence of a dative in Modern Greek, or absence of an infinitive, or the like), are rather like a traffic sign that tells drivers (as some in the United States do) that "Traffic signal sequence has changed"; ix 
this is informative if you have been to the particular intersection or road before, but on your first time there, it makes no difference if the signal or the conditions are different from what was there the day before, only that these conditions are operative today! Thus, approaching Modern Greek without the prejudice that a knowledge of Ancient Greek provides would seem to be a healthy move. In fact, this is roughly the approach that Drettas 1997 takes regarding Pontic, historically a dialect of Greek spoken in Asia Minor, describing it on its own terms in order not to invite the default position that structural features of Pontic must be understood against the backdrop of Standard Modern Greek serving as the omnipresent point of comparison. ${ }^{x}$

One possible negative consequence - probably so for Greek and maybe so for other languages — of there being so much historical information available about a familiar language, is that it can lead to a situation in which typologists do not take the language as seriously as they might. That is, Modern Greek has not made much of an impact on the typological scene, even though it has a few characteristics that are typologically striking, even if not unique or rare ${ }^{\mathrm{xi}}$ One of reasons for this relative neglect has to be, as far as Modern Greek is concerned, the overwhelming presence of Ancient Greek, which, as an historical "800pound gorilla", has overshadowed Modern Greek for many linguists. ${ }^{\text {xii }}$ 
Moreover, there is even linguistic evidence that reveals the pervasiveness of Ancient Greek even into modern times, and offers a glimpse into how others view the relationship between Ancient and Modern Greek. That is, while it is true that the term Greek in English, as well as its equivalent in French $\operatorname{grec}(q u e)$, and in other languages as well, refers to the totality of the language (as in the title of Antoine Meillet's classic work Aperçu d'une histoire de la langue grecque, which covers the Greek language from Proto-Indo-European up into the 20th century), one still has to reckon with the further fact that in English, at least, the unmarked sense of "Greek" refers to the ancient language, thus requiring the designation "Modern" for contemporary Greek; significantly, the opposite occurs with other language names in English, such as English / Old English, French / Old French, Chinese / Archaic Chinese, etc. In this way, therefore, the standard designations for the languages reveal something significant about how different stages of Greek are viewed, relative to one another.

Another factor that must also be recognized is the complication posed by the sociolinguistic situation alluded to earlier, with the constant presence of Ancient Greek and the pressure of the archaizing register of the language (katharevousa) that was consciously modeled on Ancient Greek. In particular, this has led to some intrusions into the grammar of what can loosely be called "Standard Modern Greek", and there are consequences 
for the typologist associated with approaching the language with too great a storehouse of information as to the diachronic events that led to the synchronic state under examination. This can be illustrated with two examples, one from phonology and one from syntax.

The phonological example picks up again with the issue of consonant clusters such as $x t$ and $x_{\text {_ }}$, i.e., fricative-stop and fricativefricative clusters, to which, for the purposes of this example, should be added the stop-stop cluster $k t .{ }^{\text {xii }}$ All three occur in Modern Greek, but only the $x t$ cluster is truly Demotic in nature - the other two belong to the katharevousa style of pronunciation, and/or to individual lexical items that are part of the large number of katharevousa lexical borrowings into Demotic usage (e.g. autoktonia 'suicide', from the learned language, versus xténi 'comb', a Demotic word). From the standpoint of cross-linguistic typology, one can say that the stop-stop and fricative-fricative clusters violate a featural version of the Obligatory Contour Principle (OCP), ${ }^{\text {xiv }}$ a constraint that requires that consecutive elements must show some differentiation (i.e., some "contour", since most of the cases discussed have involved tonal sequences) in their representation if they are not simply subsumed under the same representational node. By contrast, the fricativestop cluster would obey a manner-oriented form of the OCP in that the consecutive elements would show differentiation in manner. 
Since Modern Greek, approached simply as a synchronic state without concern for the history that led to that state, tolerates all three types of clusters, such an OCP cannot be regarded as an absolute constraint holding on synchronic grammars, but rather must be taken as a violable one, a desirable goal perhaps that languages aim for structurally but not a necessity for them. From a cross-linguistic standpoint, as Odden 1986 argues, this is undoubtedly the right result. Still, it is interesting to consider, in this regard, what would be said about Greek if one were to take the history seriously and discount the katharevousa elements as somehow being "alien" to the Demotic system, as is sometimes done with regard to loan words from different languages. If one were to focus just on the Demotic elements, one would have to say that Modern Greek is a language that obeys the OCP in its cluster formation (or the like) and thus is among the set of languages in which the OCP can be seen to control cluster combinatorics. This would actually be a counterfactual result, because the intrusion of the Puristic forms with $k t$ and $x_{-}$means that the OCP actually plays no role in Greek overall, and holds at best just for a subset - now historically defined only - of the lexicon. And, that has an impact on how we view the OCP, that is, as a tendency of Universal Grammar at best. Of course, one would reach that same conclusion by simply looking at Ancient Greek with its, e.g., $k t$ clusters, so the conclusion is obviously the right one, 
but the larger point here is that both the social setting for Modern Greek and the analyst's reaction to it are in part responsible for how one ends up characterizing the language typologically and, consequently, treating a putative universal (here, the OCP). One cannot typologize in a social vacuum.

The syntactic example yields similar results. Modern Greek has a number of relative clause formation strategies, an aspect of syntax that spawned considerable interest among typologists in the 1970s especially with regard to the Accessibility Hierarchy (Keenan and Comrie 1977), a ranking of which grammatical relations and structural elements in a clause were accessible to certain relativization strategies. The Accessibility Hierarchy is the basis for a number of claims about relativization embodied in a set of constraints (the "Hierarchy Constraints") that govern relativization, putatively cross-linguistically. The exact details of these claims are not relevant here, but one matter of definition that pertains to the interpretation of some of them is. In particular, Keenan and Comrie define what they call a "Primary Relativization Strategy" as a strategy that "can be used to relativize subjects" (1977: 68), and they further claim that some hierarchy constraints are valid just for primary strategies, and not for all strategies. Therefore, the determination of whether a relative clause 
formation strategy is a primary strategy or not is crucial for assessing the validity of the primary constraints on relativization.

Greek has relativization with the relative marker $p u$ that is invariant, so that its use gives a non-case-marking strategy, as well as a type with an inflected relative pronoun o opios (literally "the which"), which shows case distinctions and thus gives a case-marking strategy. ${ }^{\mathrm{xv}}$ The invariant strategy is generally considered to be the Demotic type, and is certainly so historically speaking; the inflected pronoun strategy is generally taken to reflect katharevousa usage, and thus historically it is an importation from the learned language, i.e., into standard Modern Greek usage. Nonetheless, the case-marking strategy is solidly embedded in current usage as the norm when the noun phrase that is the target of relativization is the object of a preposition, as in (1c), whereas the $p u$-type relative is usual when the target is a subject or a direct object, as in (1ab):
a. éxo
éna fílo
pu méni
S ti spárti
have/1SG a-friend/ACC REL lives/3SG in the-Sparta
'I have a friend that lives in Sparta'
b. o fílos
pu sinándises méni
s ti spárti
the-friend/NOM REL met/2SG lives/3SG in the-Sparta
'The friend that you met lives in Sparta'
c. i póli
apó tin opían
érxete 
the-city/NOM from the-which/ACC comes/3SG

íne i spárti

is/3SG the-Sparta

'The city from which he comes is Sparta'.

Based on these most typical uses, whatever the historical source of the strategy, one might be inclined to say that the case-marking strategy with $o$ opios is not a primary strategy in standard usage, as it does not relativize subjects, and thus that any properties it might show are irrelevant to the primary relativization constraints (even if they might be relevant to any constraints that do not target primary strategies). ${ }^{\mathrm{xi}}$

However, the situation is a bit more complicated, and the ultimate determination of where this strategy falls typologically again rests on the matter of taking the social context of prolonged interaction between Demotic and katharevousa into account. That is, this strategy does relativize subjects in more learned styles of Greek, as indeed it did in thoroughly katharevousa contexts. Moreover, due to the presence of the strategy in even very colloquial usage for relativizing objects of prepositions, and to the pervasive influence as well of katharevousa, the use of o opios for subjects, can be found now even in very colloquial contexts where Demotic usage might be expected to prevail, as in (2):

(2) éftase o fílos mu o opíos 


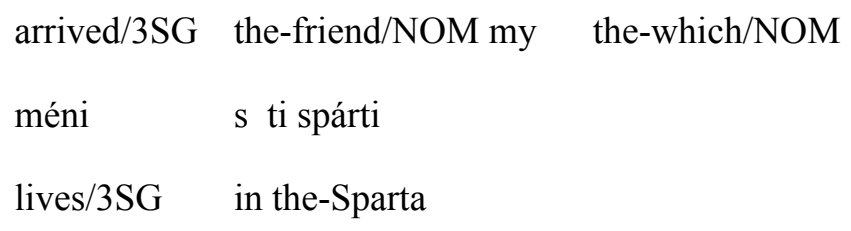

'My friend arrived who lives in Sparta'

Thus, despite its katharevousa origin and despite the apparent non-Demotic character of the use of o opios for subjects that could lead one to want to discount it as a primary strategy, the effects of dialect and register interaction in Greek have led to a situation in which the case-marking strategy must be considered to be a primary relativization strategy as far as synchronic Greek usage is concerned. Again, if one were to attempt to use historically-based information as a way of getting at "true" Demotic usage, or if one were to ignore the variation in subject-relative formation that years of competition between katharevousa and Demotic registers have caused, the picture of Greek typologically would be somewhat different.

In both of these cases, simply taking synchronic usage at face value without a concern for the history lying behind the usage seems to be the right approach for being typologically accurate. It is suggested above that the practice of trying to filter out historical accretions as somehow "alien" to a system is rather like what is sometimes done with regard to loan words and the occasional phonological disruptions they can cause. In fact, though, it seems quite reasonable to treat the influence of katharevousa 
Greek on Demotic Greek as a kind of language contact situation, essentially involving what might be termed learned borrowing. Thus what one sees with the sociolinguistics of Greek and its impact on typologizing is similar to the caveat that must always be borne in mind, namely that contact with other languages can have significant effects on a language.

Perhaps even more interesting and relevant here is that contact can lead to small "blips" in the overall typology of a language, minor intrusions that disrupt otherwise "smooth" and clean patterns. Two well-known cases involve the same element: the finite complementation introduced by $k i$ 'that' found in Persian was borrowed into Turkish, resulting in the only finite complement clauses and the only right-branching complementation in that language, and the same structure borrowed from Persian into Hindi has given the only non-correlative finite complementation in that language. To discount these structures from present-day Turkish and Hindi as being historical importations into otherwise anomaly-free patterns would belie the goals of being descriptively true to what a language presents and of accounting for the facts of languages as they are found.

Greek thus provides a basis for important methodological lessons, concerning about how external factors like grammatical preconceptions and social setting for a language can sometimes get in the way of a clear picture of how to consider the language typologically. This result, however, can 
be seen as the right result, though, since at the same time, it allows for a more realistic picture of the language, surely the typologist's desideratum. That is, somewhat paradoxically, perhaps, more information, such as the historical record that a well-known language would generally offer to the linguist, can be dangerous and can potentially lead the typologist astray, but at the same time, that greater amount of information ultimately can be a savior, enabling one to understand fully the dynamics that go into language formation by speakers, and thus being necessary for realistic grammar formation by linguists. 
i. NOTES 


\section{ii. References}

AHD

2000 The American Heritage Dictionary of the English Language. Fourth Edition. Boston: Houghton Mifflin Company

Auger, Julie

1994 More Evidence for Verbal Agreement-Marking in Colloquial French. In Santa Barbara Romance Papers: Selections from the 21st Linguistic Symposium on Romance Languages, William Ashby et al. (eds.), pp. 177-198. Amsterdam: John Benjamins Publishing Co.

1995 Clitiques pronominaux en français parlé informel: une approache morphologique. Revue québécoise de linguistique 24 (1): 21-60.

Diez, F.

1871 Grammatik der romanischen Sprachen, 2. Teil. Bonn: Eduard Weber's Buchhandlung (3rd edn.).

Dixon, R. M. W.

1982 Where Have All the Ajectives Gone? and Other Essays in syntax and semantics (Janua Linguarrum, Series Maior 107). The Hague: Mouton.

Drettas, Georges

1997 Aspects pontiques. Paris: Association de Recherche Pluridisciplinaires.

Ferguson, Charles

1959 Diglossia. Word 15: 325-340.

Goldsmith, John.

1976 Autosegmental phonology. MIT dissertation (published 1979, by Garland Press (New York)).

Holton, David, Peter Mackridge, and Irene Philippaki-Warburton 
1997 Greek. A Comprehensive Grammar of the Modern Language. London: Routledge.

Joseph, Brian D

1983 Relativization in Modern Greek. Another Look at the Accessibility Hierarchy Constraints. Lingua 60 (1): 1-24.

1994 On Weak Subjects and Pro-Drop in Greek. In Themes in Greek Linguistics (Papers from the First International Conference on Greek Linguistics, Reading, September 1993), Irene Philippaki-Warburton, Katerina Nicolaidis, and Mary Sifianou (eds.), pp. 21-32. Amsterdam: John Benjamins Publishing Co.

2000 Typological Perspectives on Modern Greek. In Studies in Greek Linguistics 20 (Proceedings of the 20th Annual Meeting of the Department of Linguistics, Faculty of Philosophy, Aristotle University of Thessaloniki), pp. 33-50. Thessaloniki: Department of Linguistics, Aristotelian University.

2002 Defining "word" in Modern Greek: a response to Philippaki-Warburton \& Spyropoulos 1999. Yearbook of Morphology 2001, pp. 87-117. Dordrecht: Kluwer Academic Publishers.

Kalitsunakis, Ioannis

1928 Grammatik der neugriechische Volkssprache. Berlin: Sammlung Göschen (reprinted 1963, Mouton).

Keenan, Edward and Bernard Comrie

1977 Noun Phrase Accessibility and Universal Grammar. Linguistic Inquiry 8: 63-99.

Leben, William.

1973. Suprasegmental phonology. MIT dissertation (published 1979, by Garland Press (New York)).

Maling, Joan.

1983. Transitive adjectives in English: A case of categorical re-analysis. In Linguistic categories: Auxiliaries and Related Puzzles. Vol. 1: Categories (Synthese 
Language Library 19), Frank Heny and Barry Richards (eds.). Dordrecht:

Kluwer Academic Publishers.

Odden, David.

1986. On the role of the Obligatory Contour Principle in phonological theory. Language

62 (2): 353-383.

Sauvageot, A.

1962 Français écrit, français parlé. Paris: Librairie Larousse.

Wolfart, H. Christoph

1973 Plains Cree: A Grammatical Study. (Transactions of the American Philosophical

Society, n.s. vol. 63, pt. 5). Philadelphia: American Philosophical Society.

Zwicky, Arnold M. and Geoffrey K. Pullum

1983. Cliticization vs. inflection: English n't. Language 59 (3): 502-513.

${ }^{\mathrm{i}}$ As, for instance, in the American Heritage Dictionary (AHD, under the entry for near). There is of course an undisputed adjective near as found in expressions such as a near miss or the near future, but that is not what Maling's discussion focused on.

ii Given that this volume is dedicated to Bob Dixon, who wrote so eloquently about adjectives in Dixon 1982, I am pleased (and hope that he is as well) that an adjective could figure in the discussion here of typology!

iii Even if transitive adjectives are found elsewhere, so that near in English is not a unique type, the point here is that finding such a type at all depends on finding it in some language to start with; if that first language attesting a particular type happens to be a well-known language, so be it - being well-known is not the same thing as being completely known!

${ }^{\text {iv }}$ Of course, we know a lot also about the history and prehistory of even less familiar languages, but such knowledge tends to be more specialized and less widely available to the average linguist looking into a particular language than for the better-documented and better-known languages.

${ }^{v}$ See Auger 1993, 1995 for perhaps the most recent defense of this view, which as she notes, actually has a rather long history, dating back to at least Diez 1871: 252.

${ }^{\mathrm{vi}}$ Many poorly described languages are spoken by small numbers of speakers, and the smaller the number of speakers, the smaller the chances are for variation. This is not to say that small speech communities have no variation - indeed, even single individuals can vary show speaker-internal variation in their speech patterns - but the chances for uniformity are greater with a smaller set of inviduals over which variation could occur.

vii This competition between the two varieties of Greek has been referred to as the "language question" and it pervaded much of Greek linguistics and Greek society for decades. In a sense, the "question" is now resolved, in that katharevousa as of 1976 ceased to have any official function in modern-day Greece, as a result of governmental reforms. Still, the effects of the years of competition remain, and have been transformed in a sense into other sorts of register differences. Thus it is not anachronistic to talk still about katharevousa and Demotic, even if the circumstances of their use in Greece have been drastically altered in the past quarter-century. 
viii "The Ancient Greek genitive is often replaced by the preposition apó with the accusative".

${ }^{\text {ix }}$ While a visitor at Bob Dixon's Research Centre for Linguistic Typology in 2001, I had occasion to see the Australian version of this sign: with the construction of a new road near the La Trobe University wildlife reserve, a sign was posted saying "Changed Road Conditions Ahead". The first time I encountered it, I was of course curious as to what the conditions had been changed from, but what was most salient to me was the way they were at the moment I was trying to negotiate the road!

${ }^{\mathrm{x}}$ Indeed, the result of Drettas's tabula rasa approach is that he is convinced that Pontic should be considered now a separate language, distinct from its source language and not a dialect of Greek, a view that seems eminently reasonable, given the rather striking differences between Pontic and other varieties of Greek.

${ }^{\mathrm{xi}}$ I discuss these features in Joseph 2000, but can mention a few here: a phonological system with a skewing of stops versus fricatives (fewer stops than fricatives), and with voiced stops that are either positionally restricted or weakly represented in terms of frequency (as opposed to robust voiceless stops); a morphosyntax that recognizes a multiple distinction in pronouns among strong (emphatic) forms, weak (so-called "clitic" forms), and for the third person nominatives, an intermediate-strength weak form (not just a phonological reduction) whereas for non-third person nominative forms, "weakened" forms that are only phonological reductions of strong forms (see Joseph 1994, 2002 for some discussion); a syntax with relative clause formation strategies that challenge aspects of the Keenan-Comrie Accessibility Hierarchy (e.g., whether individual relativization strategies always apply over continous segments of the Accessibility Hierarchy - Greek suggests not, as discussed in Joseph 1983); etc.

xii The reference here is to the joke: "Where does an 800-pound gorilla sit? Answer: Anywhere he wants to!".

xiii The situation is similar with clusters having labials as the initial element: $p t, f t$, and $f_{-}$all occur, but only $f t$ is historically Demotic.

${ }^{\text {xiv }}$ I draw here on the excellent discussion in Odden 1986 of this constraint, first proposed by Leben 1973, and later elaborated on (and named) by Goldsmith 1976, with regard to the representation of sequences of tones. Odden clarifies the status of the constraint in Universal Grammar, as noted below.

${ }^{\mathrm{xv}}$ There are some other types that are based on these two with slight structural "wrinkles", but they are not of concern for the point being made here; see Joseph 1983 for further discussion.

${ }^{x v i}$ Indeed, working with a relatively limited data base (understandably, given the nature of their crosslinguistic survey), this was the position that Keenan and Comrie 1977 took with regard to Greek. 